\title{
Product Characteristics of Sludge Pyrolysis and Adsorption Performance of Metals by Char
}

\author{
Kuo-Hsiung Lin ${ }^{1}$, Jiun-Horng Tsai ${ }^{2,3}$, Zhi-Wei Chou ${ }^{1}$ and Hung-Lung Chiang ${ }^{4,5, *}$ \\ 1 Department of Environmental Engineering and Science, Fooyin University, Kaohsiung 831301, Taiwan; \\ xx407@fy.edu.tw (K.-H.L.); kleo820801@gmail.com (Z.-W.C.) \\ 2 Department of Environmental Engineering, National Cheng Kung University, Tainan 701, Taiwan; \\ jhtsai@ncku.edu.tw \\ 3 Research Center for Climate Change and Environment Quality, National Cheng Kung University, \\ Tainan 701, Taiwan \\ 4 Department of Occupational Safety and Health, China Medical University, Taichung 406040, Taiwan \\ 5 Department of Safety Health and Environmental Engineering, National Yunlin University of Science and \\ Technology, Yunlin 64002, Taiwan \\ * Correspondence: hlchiang@yuntech.edu.tw; Tel.: +886-5-536-1489; Fax: +886-5-536-1353
}

check for updates

Citation: Lin, K.-H.; Tsai, J.-H.; Chou, Z.-W.; Chiang, H.-L. Product Characteristics of Sludge Pyrolysis and Adsorption Performance of Metals by Char. Sustainability 2021, 13, 12125. https://doi.org/10.3390/ su132112125

Academic Editor: Elena Rada

Received: 1 September 2021

Accepted: 29 October 2021

Published: 3 November 2021

Publisher's Note: MDPI stays neutral with regard to jurisdictional claims in published maps and institutional affiliations.

Copyright: (c) 2021 by the authors. Licensee MDPI, Basel, Switzerland. This article is an open access article distributed under the terms and conditions of the Creative Commons Attribution (CC BY) license (https:// creativecommons.org/licenses/by/ $4.0 /)$.

\begin{abstract}
The microwave heating system was used for sludge pyrolysis. The raw sludge and $\mathrm{KOH}-$ immersed sludge were pyrolyzed and their product characteristics were determined. The research results are advantageous to understand the influence of $\mathrm{KOH}$ activation on characteristics of pyrolysis products and the adsorption performance of metals in char. In the case of a high temperature and high $\mathrm{KOH}$ dose, most of the lost mass from sludge pyrolysis was converted into gaseous products instead of oil. The heat values of liquid oils were $40.86-41.39 \mathrm{MJ} \mathrm{kg}^{-1}$, which has the potential for use as fuels. The use of a higher $\mathrm{KOH}$ dose for sludge pyrolysis is beneficial to the porosity development and generates a mesopore structure. The results from adsorption tests indicate that precipitation could be the dominant adsorption mechanism due to the binding between alkaline anion and carbonate and metal ions with a strong chemical affinity. The high $\mathrm{KOH}$ dose sludge adsorbent has a remarkable adsorption performance and can be used as adsorbent for the removal of the studied metals.
\end{abstract}

Keywords: sludge; potassium hydroxide $(\mathrm{KOH})$; mesopore; precipitation

\section{Introduction}

Waste disposal is an important issue in industrialized countries, especially in urban areas. Public concerns focus on the release of contaminants into the environment and ecological systems, which can pose serious risks to human health and the environment. Therefore, the development of reuse procedures is important work for the safe disposal of waste. Bio-sludge, which has a high organic content, is a product of wastewater treatment facilities. Waste sludge disposal can account for a high fraction of the operating costs of wastewater treatment plants (WWTPs) [1]. Due to its rapidly increasing amount and potential risks for the environment and human health, the sludge issue has raised significant public concerns. Reduce, recycle, and reuse are important concepts for sludge disposal [2].

Sludge from the biological treatment of wastewater can be considered a biomass resource due to its high organic content (lipids or fats, carbohydrates, and proteins) $[3,4]$. The organic fraction of sludge can be a source of oil and gas fuels for energy or for use in valuable chemical products after suitable treatment [5-8]. The thermochemical processes of sludge, such as pyrolysis, gasification, and combustion, have been reviewed in detail in terms of process enhancements and the recovery of energy and resources from sludge [9]. The pyrolysis technique for sludge disposal offers many advantages, including inhibiting heavy metal vaporization due to a decrease of the pyrolysis temperature, reducing the leaching of heavy metals from the pyrolysis carbonaceous residue [10], and offering 
relatively low pollution control cost compared to combustion techniques [11,12]. Due to the high moisture content of the sludge, microwave systems may be used for drying and pyrolysis to improve the energy efficiency of the process.

Some biomass materials, such as evergreen oak, bamboo, and coconut shells, can be used as raw materials for activated carbon [13]. Biomass reuse should be considered for the sustainable preservation and protection of the environment. There are two activation methods for biomass materials to develop porous structures: (1) physical activation, such as steam or carbon dioxide, for gasification and carbonization to produce char; and (2) chemical activation with a chemical reagent, such as zinc chloride, phosphoric acid, or potassium hydroxide. Specifically, chemical activation has the obvious advantages of a shorter processing time, lower pyrolysis temperature, lower energy consumption, and larger specific surface area [14], so it may be suitable for the development of sludge-based adsorbents.

One drawback of $\mathrm{ZnCl}_{2}$ activation, compared with alkaline and phosphoric acid activation, is that zinc is a heavy metal, which can pollute the environment. Catalysts $\mathrm{KOH}$, $\mathrm{KOH} / \mathrm{AC}$, and $\mathrm{KOH} / \mathrm{CaO}$ can conduct the trans-esterification reaction with sludge under alkaline conditions and produce high-quality stable bio-oil [15]. In addition, the alkaline catalysts react with the fatty acids of sludge, and reaction mixtures can be easily separated, thereby simplifying the operating conditions for recycling materials and reducing environmental pollution [16-18]. KOH activation can enhance various materials (such as tires [19], peel [20], and sludge $[15,21]$ to be adsorbents for the removal of pollutants from various media. For sludge-based adsorbents, $\mathrm{KOH}$ was regarded as an effective activation reagent, producing sludge adsorbents with a high specific surface area [22,23].

Heavy metals, such as cadmium, chromium, copper, lead, mercury, nickel, and zinc, are of concern because of their toxicity and longevity in the environment and their health effects on human [21,23]. Many studies have reported that sludge-derived adsorbents can be applied for the removal of heavy metals under various conditions [21]. Sludge-based adsorbents prepared by $\mathrm{KOH}$ activation showed the highest surface area with BrunauerEmmett-Teller (BET) theory [24] and were used for the removal of $\mathrm{Cu}(\mathrm{II})$ and $\mathrm{Pb}$ (II) from liquid solutions [25]. The physicochemical characteristics (such as surface area, porosity, $\mathrm{pH}$, surface charge, functional groups, and mineral contents) of biochar could affect its sorption capacity of metals [26]. For biochar, the removal mechanisms of heavy metals from aqueous solutions could be chemical interaction, physical sorption on surface sites, surface precipitation and complexation, and ion exchange (e.g., $\mathrm{Na}^{+}, \mathrm{Ca}^{2+}$, and $\mathrm{Mg}^{2+}$ ) [27-29]. In any case, the use of $\mathrm{KOH}$ as a sludge pyrolysis activator still requires careful evaluation in terms of the operating conditions and product characteristics, because this is related to the suitability and safety in the use of the derived oil and char.

In this work, microwave pyrolysis technology was employed to treat sludge from a petrochemical wastewater treatment plant. The raw sludge and $\mathrm{KOH}$-immersed sludge were pyrolyzed and their mass fraction distributions of the products were determined. The characteristics of oil and char, and pore development in char were analyzed, for which the influence of $\mathrm{KOH}$ activation was also compared. The adsorption capacities of $\mathrm{Cd}(\mathrm{II})$, $\mathrm{Pb}(\mathrm{II}), \mathrm{Zn}(\mathrm{II})$, and $\mathrm{Ni}(\mathrm{II})$ on sludge-derived adsorbents were measured, and the possible adsorption mechanism was explored.

\section{Experimental}

\subsection{Materials}

Sludge samples were obtained from the wastewater treatment plant of a petrochemical industry in southern Taiwan. Sludge cake obtained from an activated sludge process after the mechanical dewatering process and the biosludge contains microorganisms. The moisture content was determined at $105 \pm 5{ }^{\circ} \mathrm{C}$ by ASTM D3173-02 [30] and the ash content was determined at $800 \pm 20^{\circ} \mathrm{C}$ and followed the method ASTM D3174-02 [31]. Volatile matter was determined by using the method ASTM D3175-02 [32]. The fixed carbon is a calculated value. It is the resultant of the summation of percentage moisture, 
ash, and volatile matter subtracted from 100 . The raw sludge cakes contained $81 \pm 4$ wt. $\%$ water, $6.8 \pm 0.5 \mathrm{wt} . \%$ ash, $11.6 \pm 0.8 \mathrm{wt}$. $\%$ volatile matter, and $0.7 \pm 0.06 \mathrm{wt} . \%$ fixed carbon. Before pyrolysis, the sludge was stored at $4{ }^{\circ} \mathrm{C}$.

\subsection{Sludge Microwave Pyrolysis}

A multi-mode microwave oven was used for sludge drying and pyrolysis in a single process. The microwave oven can be operated with a maximum input power of $900 \mathrm{~W}$ at a frequency of $2450 \mathrm{MHz}$. First, $100 \mathrm{~g}$ of sludge sample were put into a quartz tube reactor (length $25 \mathrm{~cm}$, inner diameter $5.5 \mathrm{~cm}$, outer diameter $9 \mathrm{~cm}$ ), outside of which was a quartz container, and placed in the microwave oven. During the period of sludge pyrolysis, $\mathrm{N}_{2}$ gas was introduced and passed through the tube reactor at a rate of $200 \mathrm{~mL} / \mathrm{min}$ to maintain an oxygen-free state. A rubber-silicon-ring and stainless-steel cap were selected to seal the tube reactor. A thermocouple $\left(0-1000{ }^{\circ} \mathrm{C}\right)$ was installed in the reactor and connected to a temperature controller. The gas emitted during the experiment was cooled by an ice-water bath condenser, and the condensable vapor was collected by a liquid collector. The liquid oil was separated from the primary pyrolysis liquid product by distillation at $120{ }^{\circ} \mathrm{C}\left(20^{\circ} \mathrm{C} \mathrm{min}^{-1}\right)$ for $10 \mathrm{~min}$ to remove water. The oil was weighed to determine the yield of liquid oil. Microwave pyrolysis was conducted on three replicate samples for each pyrolysis temperature.

\subsection{Sludge-Derived Adsorbent}

The raw sludge was immersed and mixed with $\mathrm{KOH}$ at mass ratios ( $\mathrm{KOH}$ :dried sludge, by weight) of 0.25:1 (low $\mathrm{KOH}$ dose) and 0.5:1 (high $\mathrm{KOH}$ dose). Before microwave pyrolysis, the mixture (added $\mathrm{KOH}$ in sludge) was heated in a separate oven at $80{ }^{\circ} \mathrm{C}$ for $4 \mathrm{~h}$. With microwave heating, the sludge sample was heated to $135^{\circ} \mathrm{C}$ and held for $3 \mathrm{~min}$ for dehydration. Then, it was continuously heated to the desired temperature and held for $30 \mathrm{~min}$. The raw sludge and $\mathrm{KOH}$-immersed sludge were pyrolyzed at 400, 500, and $600{ }^{\circ} \mathrm{C}$ for $30 \mathrm{~min}$. The pyrolysis residues (char) were leached with $0.2 \mathrm{M} \mathrm{HCl}$ solution and then washed with distilled water to remove the $\mathrm{KOH}$ and impurities, until the rinsed water reached a $\mathrm{pH}$ of $6.8 \pm 0.2$ and the electrical conductivity was close to distilled water. After that, the washed char was dried in an oven at $105^{\circ} \mathrm{C}$ for $48 \mathrm{~h}$ and weighed to determine the yield of solid product. The final adsorbent derived from pyrolysis char was transferred to a desiccator until use for the analysis and adsorption test.

\subsection{Elemental Constituents}

An element analyzer (Heraeus CHN-O Rapid Element analyzer, Heraeus Incorporated, Yardley, PA, USA) was employed to determine the major element contents, including carbon, hydrogen, and nitrogen, in the dried raw sludge and pyrolysis oil. Sulfur and chloride concentrations were measured with a Tacussel Coloumax 78 (USA) automatic coulometric titrator. The oxygen content of the dried raw sludge was calculated by subtracting the summation of N, H, C, S, and ash content from $100 \%$. The oxygen content of the oil was calculated in the same way, but the ash content can be ignored. Sulfanilic acid and 1-chloro-2, 4-dinitrobenzene were selected as standards of the elemental analyzer.

X-ray fluorescence analysis was used to determine the content of trace elements in dry raw sludge and sludge-derived adsorbents. An instrument (SPECTRO model 300T Benchtop Multi-Channel analyzer) equipped with a titanium (Ti) target X-ray tube and a high-resolution detector (ASOMA Instruments Inc., Austin, TX, USA) was used. Samples were ground and sieved to ensure a uniform sludge particle size before analysis.

\subsection{Organic Constituents of Liquid Oil}

The organic constituents of liquid oil were detected using a gas chromatograph equipped with a DB-5 column (Agilent J\&W) with $30 \mathrm{~m}$ length, $0.25 \mathrm{~mm}$ internal diameter, $0.25 \mu \mathrm{m}$ film thickness, and a mass detector (GC-MS, model QP-2010; Shimadzu, Japan). The temperature program of the GC oven was set to increase at a rate of $5^{\circ} \mathrm{C} \mathrm{min}$ m from $^{-1}$ 
60 (the initial time $10 \mathrm{~min}$ ) to $325^{\circ} \mathrm{C}$. Helium was used as the carrier gas with a flow rate of $2 \mathrm{~mL} \mathrm{~min}^{-1}$. For each peak, compounds were identified by comparing the mass spectra with those of the reference compounds available in the library. The relative contents of the liquid constituents were expressed as the percentage of area under the curve for each peak.

\subsection{Pore Characteristics of Sludge-Derived Adsorbents}

After pyrolysis, the sludge-derived adsorbents were analyzed to determine their physical characteristics, including the specific surface area, pore volume distribution, and pore diameter, using $\mathrm{N}_{2}$ (gas) adsorption (in liquid $\mathrm{N}_{2}$ condition at 77K) in an ASAP 2010 micropore analyzer. The BET method [24] and Barrett-Jovner-Halenda (BJH) method [33] were selected to determine the surface area and pore volume distribution, respectively. Silica-alumina, alumina, and molecular sieves were purchased from Micrometrics and used in quality assurance and quality control procedures to determine the pore characteristics of sludge-derived adsorbents.

\subsection{Metal Adsorption}

$\mathrm{Cd}(\mathrm{II}), \mathrm{Pb}(\mathrm{II}), \mathrm{Ni}(\mathrm{II})$, and $\mathrm{Zn}(\mathrm{II})$ were selected to evaluate the adsorption capacity of sludge-derived adsorbents. The $\mathrm{Cd}(\mathrm{II})$ stock solution was prepared by dissolving cadmium nitrate tetrahydrate $\left(\mathrm{Cd}\left(\mathrm{NO}_{3}\right)_{2} \cdot 4 \mathrm{H}_{2} \mathrm{O}\right)$ Merck KGaA, Darmstadt, Germany) in $2 \%$ nitric acid. $\mathrm{Pb}(\mathrm{II}), \mathrm{Ni}(\mathrm{II})$, and $\mathrm{Zn}(\mathrm{II})$ standard nitrate solutions (Merck KGaA, Darmstadt, Germany) were used as the stock solutions of lead, nickel, and zinc, respectively. An atomic absorption spectrometer (AA, Perkin Elmer model 3110) was employed to determine the metal content in the solution. The individual standard solution of the studied metal ions was prepared by dilution from stock solution (each of $1000 \mathrm{mg} / \mathrm{L}$ ). The calibration curves (included 5 standard solutions with distinct concentrations) were established using the single standard solution of $\mathrm{Cd}(\mathrm{II}), \mathrm{Pb}(\mathrm{II}), \mathrm{Ni}(\mathrm{II})$, and $\mathrm{Zn}(\mathrm{II})$, respectively.

The adsorption of a single metal ion was conducted for the adsorption isotherm of each metal ion. A preliminary experiment showed that the adsorption of the four metal ions (200 $\mathrm{mg} \mathrm{L}^{-1}$; liquid: solid = $1 \mathrm{~L}: 0.2 \mathrm{~g}$ ) on sludge-derived adsorbents reached equilibrium within $24 \mathrm{~h}$. Therefore, the adsorption isotherms experiments were conducted with a duration time of $24 \mathrm{~h}$. For each metal ion, the ion solutions were in the concentration range of $50-800 \mathrm{mg} / \mathrm{L}$ and the $\mathrm{pH}$ was regulated to 6.0 with diluted $\mathrm{HCl}$ and $\mathrm{NaOH}$ aqueous solution. Sludge-derived adsorbent particles $(0.1 \mathrm{~g})$ were put into a $50 \mathrm{~mL}$ metal solution under a $25 \pm 1{ }^{\circ} \mathrm{C}$ water bath with a $100 \mathrm{rpm}$ vibrator for $24 \mathrm{~h}$. Then, the mixture was filtered through a $0.45 \mu \mathrm{m}$ filter and the filtrate was collected. The ion concentration in the solution was determined, and the adsorption capacity of sludge-derived adsorbents was calculated by the difference between the initial and final equilibrium ion concentration.

\subsection{Data Analysis}

The Langmuir model was selected to describe the metal ion adsorption isotherms as the following equation:

$$
q=q_{m} K C_{e} / 1+K C_{e}
$$

where $q\left(\mathrm{mg} \mathrm{g}^{-1}\right)$ is the adsorption capacity, $q_{m}\left(\mathrm{mg} \mathrm{g}^{-1}\right)$ is the maximum adsorption capacity of the monolayer, $K\left(\mathrm{~L} \mathrm{mg}^{-1}\right)$ is the constant related to the affinity, and $C_{e}\left(\mathrm{mg} \mathrm{L}^{-1}\right)$ is the ion concentration at equilibrium. The Langmuir model explains adsorption by assuming monolayer adsorption onto a surface with homogenous adsorption sites without ion interaction with each other. Equation (1) can be rewritten to linear form as follows:

$$
1 / q=\left(1 / q_{m} K\right) 1 / C_{e}+1 / q_{m}
$$

According to Equation (2), the Langmuir model was applied to fit the experimental data (including all three replicate tests), and the statistical parameters $\left(q_{m}\right.$ and $\left.K\right)$ were estimated using the linear regression approach in an SPSS statistical package (version 19.0.0; 
IBM Corp., Armonk, NY, USA). The optimum values of the parameters were selected with the least-square method.

One-way analysis of variance (ANOVA) was used to analyze results for pyrolysis temperatures and $\mathrm{KOH}$ doses associated with product data, element data, organic constituent data for oil, and pore characteristic data. Where appropriate, the $t$-test was used for pairwise comparisons of means. The ANOVA and $t$-test (version 19.0.0; IBM Corp., Armonk, NY, USA) were both performed at $\alpha=0.05$.

\section{Results and Discussion}

\subsection{Sludge Pyrolysis and Mass Distribution}

As described in Section 2, the yields of both liquid oil and char (referred to as sludgederived adsorbent) were determined, and then the yield of gas was calculated by the difference. As seen in all cases of Table 1, a higher pyrolysis temperature reduces the yield of char and increases the yields of both liquid oil and gas. With an increasing pyrolysis temperature from 500 to $600{ }^{\circ} \mathrm{C}$, for the $\mathrm{KOH}$-immersed sludge, the increment of gas yield (32-41 wt.\%) is much higher than the increment of oil yield (13-14 wt.\%).

Table 1. Major elemental composition in liquid oils and mass fraction of products after pyrolyzing raw sludge and $\mathrm{KOH}$-immersed sludge at different temperatures.

\begin{tabular}{|c|c|c|c|c|c|c|c|c|c|}
\hline $\begin{array}{l}\mathrm{KOH} / \text { Sludge } \\
\text { Ratio }\end{array}$ & & 0 & & & 0.25 & & & 0.5 & \\
\hline Temperature ${ }^{\circ} \mathrm{C}$ & 400 & 500 & 600 & 400 & 500 & 600 & 400 & 500 & 600 \\
\hline \multicolumn{10}{|l|}{ Mass fraction } \\
\hline Char (wt.\%) & $69 \pm 3.5$ & $63 \pm 2.9$ & $59 \pm 2.1$ & $64 \pm 3.8$ & $60 \pm 3.2$ & $54 \pm 3.4$ & $62 \pm 4.2$ & $55 \pm 3.5$ & $45 \pm 3.1$ \\
\hline Liquid oil (wt.\%) & $16 \pm 1.4$ & $17 \pm 1.3$ & $20 \pm 1.6$ & $14 \pm 1.2$ & $16 \pm 1.5$ & $17 \pm 1.3$ & $8.0 \pm 0.6$ & $13 \pm 1.1$ & $14 \pm 1.2$ \\
\hline Gas (wt.\%) & $15 \pm 1.2$ & $20 \pm 1.7$ & $21 \pm 1.8$ & $22 \pm 1.6$ & $24 \pm 2.2$ & $29 \pm 2.3$ & $30 \pm 2.3$ & $32 \pm 2.5$ & $41 \pm 3.4$ \\
\hline \multicolumn{10}{|l|}{$\begin{array}{l}\text { Major element } \\
\text { in oil }\end{array}$} \\
\hline N (wt.\%) & $2.1 \pm 0.15$ & $2.0 \pm 0.12$ & $1.7 \pm 0.11$ & $1.5 \pm 0.09$ & $1.4 \pm 0.09$ & $1.2 \pm 0.08$ & $2.1 \pm 0.10$ & $1.2 \pm 0.06$ & $1.1 \pm 0.05$ \\
\hline C (wt.\%) & $80.7 \pm 4.26$ & $81.6 \pm 5.05$ & $77.1 \pm 4.45$ & $73.7 \pm 3.83$ & $74.3 \pm 4.11$ & $70.4 \pm 3.77$ & $77.9 \pm 3.18$ & $74.1 \pm 3.32$ & $66.5 \pm 3.47$ \\
\hline S (wt.\%) & $3.8 \pm 0.12$ & $1.5 \pm 0.10$ & $1.3 \pm 0.09$ & $0.9 \pm 0.07$ & $0.8 \pm 0.06$ & $0.9 \pm 0.06$ & $0.7 \pm 0.04$ & $0.8 \pm 0.05$ & $0.8 \pm 0.06$ \\
\hline H (wt.\%) & $3.9 \pm 0.18$ & $4.5 \pm 0.28$ & $4.2 \pm 0.24$ & $3.8 \pm 0.27$ & $3.6 \pm 0.25$ & $4.3 \pm 0.22$ & $4.1 \pm 0.23$ & $3.4 \pm 0.21$ & $3.9 \pm 0.26$ \\
\hline
\end{tabular}

Furthermore, the pyrolysis products from raw sludge were 15-21 wt. $\%$ in the gas phase, 16-20 wt.\% in the liquid oil phase, and 69-59 wt.\% in char at temperatures of $400-600{ }^{\circ} \mathrm{C}$ (shown in Table 1). The mass fractions of pyrolysis products were expressed on the dried raw sludge base. Due to the addition of $\mathrm{KOH}$, the yields of both char and liquid oil were reduced, while the yield of gas was increased. Higher $\mathrm{KOH}$ doses resulted in the same tendency and the effect of $\mathrm{KOH}$ activation was more significant. The results suggest that the mass loss of $\mathrm{KOH}$-immersed sludge tends to produce lighter molecules, under high-temperature pyrolysis conditions, without being condensed and collected as liquid oil. $\mathrm{KOH}$ immersion seems to improve the decomposition of large molecular intermediates and forms small molecules as reported by the literature [34]. Especially at high temperatures, most of the lost mass was converted into gaseous products instead of liquid oil.

\subsection{Elemental and Organic Constituents of Liquid Oil}

The major element contents of the dried raw sludge $\left(105 \pm 5^{\circ} \mathrm{C}\right.$, overnight $)$ were $32.8 \%$ carbon, $6.1 \%$ hydrogen, $2.6 \%$ nitrogen, and $3.9 \%$ sulphur. The chlorine content was less than $0.01 \mathrm{wt} . \%$. At pyrolysis temperatures of $400-600{ }^{\circ} \mathrm{C}$, the dominant element components in liquid oil from raw sludge were carbon (77-81 wt.\%), hydrogen (3.9-4.5 wt.\%), nitrogen (1.7-2.1 wt.\%), and sulfur (1.3-3.8 wt.\%) (shown in Table 1). The carbon, sulfur, and nitrogen contents decreased in liquid oil due to the addition of $\mathrm{KOH}$. However, the hydrogen content in liquid oil was slightly affected by $\mathrm{KOH}$.

For raw sludge pyrolysis at $400{ }^{\circ} \mathrm{C}$, the dominant constituents of the oil were monoethyl toluene (C9) (6.9\%), trimethyl benzene (C9) (5.7\%), diethyl benzene(C10) (5.8\%), mo- 
noethyl xylene (C10) (5.5\%), tetramethyl benzene (C10) (5.5\%), 1+2+3-methylindene (C10) (7.6\%), naphthalene (C10) (8.8\%), 1-methylnaphthalene (C11) (8.8\%), 2-methylnaphthalene (C11) (6.0\%), and dimethyl naphthalene (C12) (11.5\%) (shown as Table 2). Some cases of these compounds, such as diethyl benzene, tetramethyl benzene, naphthalene, 1-methylnaphthalene, 2-methylnaphthalene, and dimethyl naphthalene, significantly decreased in their contents at high temperatures (up to $600^{\circ} \mathrm{C}$ ). Most of the identifiable species were aromatics, which could come from the cracking of the raw material itself or formation by restructuring of organic compounds with the pyrolysis process. A previous study indicated that $\mathrm{KOH}$ first reacts with active oxygen-containing substances under the process of biomass pyrolysis, which can remove most of the oxygen-containing groups, thereby releasing a large amount of free radicals. A certain amount of $\mathrm{KOH}$ and free radicals can react with pyrolysis intermediates to promote deoxygenation and aromatization reactions (introducing high aromatic species in oil). These processes also release many gaseous products. In addition, certain free radicals can also be directly converted into gaseous products. These processes lead to a large reduction in bio-oil and a sharp increase in gaseous products [35]. As shown in Table 2, for the $\mathrm{KOH}$-immersed sludge pyrolysis $(\mathrm{KOH} /$ sludge ratio: 0.5$)$, monoethyl toluene, trimethyl benzene, and dicyclopentadiene (C10) cannot be detected at $400-600{ }^{\circ} \mathrm{C}$. At temperature of $600{ }^{\circ} \mathrm{C}$, diethyl benzene, monoethyl xylene, and tetramethyl benzene also disappear further. Different from the pyrolysis of raw sludge, some intermediate products are easily decomposed into gaseous substances due to the addition of $\mathrm{KOH}$, and some major organic components cannot be found in the oil.

Table 2. Liquid oil constituents for raw sludge and $\mathrm{KOH}$-immersed sludge after various pyrolytic temperatures.

\begin{tabular}{|c|c|c|c|c|c|c|c|}
\hline \multirow{2}{*}{ Compounds } & \multirow{2}{*}{ Formula } & \multicolumn{3}{|c|}{ KOH/Sludge Ratio: 0} & \multicolumn{3}{|c|}{ KOH/Sludge Ratio: 0.5} \\
\hline & & $400{ }^{\circ} \mathrm{C}$ & $500{ }^{\circ} \mathrm{C}$ & $600{ }^{\circ} \mathrm{C}$ & $400{ }^{\circ} \mathrm{C}$ & $500{ }^{\circ} \mathrm{C}$ & $600{ }^{\circ} \mathrm{C}$ \\
\hline Monoethyl toluene mixture & $\mathrm{C}_{9} \mathrm{H}_{12}$ & $6.87 \pm 0.27$ & $4.11 \pm 0.21$ & $5.68 \pm 0.17$ & *nd & *nd & *nd \\
\hline Trimethylbenzene mixture & $\mathrm{C}_{9} \mathrm{H}_{12}$ & $5.38 \pm 0.27$ & $4.63 \pm 0.32$ & $5.71 \pm 0.29$ & ${ }^{*}$ nd & *nd & *nd \\
\hline Dicyclopentadiene & $\mathrm{C}_{10} \mathrm{H}_{12}$ & $3.47 \pm 0.10$ & $1.47 \pm 0.04$ & $1.77 \pm 0.07$ & *nd & *nd & *nd \\
\hline Indene & $\mathrm{C}_{9} \mathrm{H}_{8}$ & $2.45 \pm 0.15$ & $2.72 \pm 0.11$ & $3.36 \pm 0.24$ & $2.18 \pm 0.17$ & $3.05 \pm 0.27$ & $3.37 \pm 0.34$ \\
\hline Diethylbenzene mixture & $\mathrm{C}_{10} \mathrm{H}_{14}$ & $5.77 \pm 0.23$ & $2.26 \pm 0.14$ & $2.47 \pm 0.21$ & $2.41 \pm 0.14$ & $3.24 \pm 0.16$ & *nd \\
\hline Monoethyl xylene mixture & $\mathrm{C}_{10} \mathrm{H}_{14}$ & $5.45 \pm 0.27$ & $5.46 \pm 0.27$ & $5.01 \pm 0.32$ & $6.23 \pm 0.56$ & $10.17 \pm 0.71$ & *nd \\
\hline Pyrindan & $\mathrm{C}_{8} \mathrm{H}_{9} \mathrm{~N}$ & *nd & ${ }^{*}$ nd & *nd & *nd & *nd & $3.26 \pm 0.39$ \\
\hline Indolene & $\mathrm{C}_{8} \mathrm{H}_{9} \mathrm{~N}$ & ${ }^{*}$ nd & *nd & ${ }^{*}$ nd & *nd & *nd & $2.29 \pm 0.21$ \\
\hline Tetramethyl benzene mixture & $\mathrm{C}_{10} \mathrm{H}_{14}$ & $5.54 \pm 0.33$ & $3.75 \pm 0.15$ & $3.84 \pm 0.31$ & $4.44 \pm 0.36$ & $5.01 \pm 0.32$ & ${ }^{*}$ nd \\
\hline 1+2+3-Methylindene & $\mathrm{C}_{10} \mathrm{H}_{10}$ & $7.64 \pm 0.23$ & $6.26 \pm 0.38$ & $7.37 \pm 0.52$ & $6.51 \pm 0.33$ & $8.21 \pm 0.74$ & $6.45 \pm 0.45$ \\
\hline Naphthalene & $\mathrm{C}_{10} \mathrm{H}_{8}$ & $8.75 \pm 0.35$ & $6.23 \pm 0.19$ & $6.37 \pm 0.33$ & $6.42 \pm 0.51$ & $8.41 \pm 0.34$ & $12.40 \pm 0.62$ \\
\hline 1-Methylnaphthalene & $\mathrm{C}_{11} \mathrm{H}_{10}$ & $8.76 \pm 0.53$ & $5.54 \pm 0.33$ & $5.32 \pm 0.21$ & $9.95 \pm 0.63$ & $11.20 \pm 0.22$ & $5.39 \pm 0.43$ \\
\hline 2-Methylnaphthalene & $\mathrm{C}_{11} \mathrm{H}_{10}$ & $5.95 \pm 0.30$ & $4.20 \pm 0.13$ & $3.92 \pm 0.24$ & $7.37 \pm 0.52$ & $7.82 \pm 0.63$ & $9.26 \pm 1.02$ \\
\hline 4-Phenylbutyronitrile & $\mathrm{C}_{10} \mathrm{H}_{11} \mathrm{~N}$ & *nd & *nd & *nd & *nd & *nd & $3.19 \pm 0.29$ \\
\hline Biphenyl & $\mathrm{C}_{12} \mathrm{H}_{10}$ & $1.74 \pm 0.07$ & $1.81 \pm 0.07$ & $1.66 \pm 0.13$ & $1.91 \pm 0.17$ & $1.93 \pm 0.13$ & $3.48 \pm 0.21$ \\
\hline 1+2-Ethylnaphthalene & $\mathrm{C}_{12} \mathrm{H}_{12}$ & *nd & *nd & *nd & $3.52 \pm 0.32$ & $3.02 \pm 0.12$ & $1.28 \pm 0.12$ \\
\hline $\begin{array}{l}\text { Dimethylnaphthalene } \\
\text { mixture }\end{array}$ & $\mathrm{C}_{12} \mathrm{H}_{12}$ & $11.53 \pm 0.69$ & $10.24 \pm 0.51$ & $7.74 \pm 0.23$ & $10.11 \pm 0.71$ & $10.56 \pm 0.95$ & $3.05 \pm 0.15$ \\
\hline Biphenylene & $\mathrm{C}_{12} \mathrm{H}_{8}$ & *nd & *nd & *nd & $2.37 \pm 0.12$ & $2.30 \pm 0.25$ & *nd \\
\hline $2+3+4$-Phenyltoluene & $\mathrm{C}_{13} \mathrm{H}_{12}$ & $2.81 \pm 0.20$ & $2.95 \pm 0.15$ & $2.53 \pm 0.18$ & $4.16 \pm 0.33$ & $3.74 \pm 0.37$ & $5.32 \pm 0.21$ \\
\hline $\begin{array}{l}\text { Trimethylnaphthalene } \\
\text { mixture }\end{array}$ & $\mathrm{C}_{13} \mathrm{H}_{14}$ & $1.78 \pm 0.05$ & $2.77 \pm 0.19$ & $1.89 \pm 0.08$ & $0.94 \pm 0.07$ & $0.73 \pm 0.04$ & *nd \\
\hline 1,3-Diphenylpropane & $\mathrm{C}_{15} \mathrm{H}_{16}$ & *nd & *nd & *nd & *nd & *nd & $10.85 \pm 0.87$ \\
\hline Phenanthrene & $\mathrm{C}_{14} \mathrm{H}_{10}$ & $1.11 \pm 0.06$ & $2.24 \pm 0.09$ & $1.97 \pm 0.16$ & $3.74 \pm 0.34$ & $3.37 \pm 0.27$ & $0.93 \pm 0.07$ \\
\hline Sum $(\%)$ & & $84.90 \pm 4.25$ & $66.64 \pm 4.66$ & $66.61 \pm 3.83$ & $72.26 \pm 6.48$ & $82.76 \pm 7.97$ & $70.88 \pm 6.74$ \\
\hline
\end{tabular}

*nd: not detectable.

In addition, some species (e.g., monoethyl xylene, 1-methylnaphthalene, and 2-methylnaphthalene) increase in their contents significantly due to the addition of $\mathrm{KOH}$, at $400-500{ }^{\circ} \mathrm{C}$. As mentioned previously, the addition of $\mathrm{KOH}$ causes a large number of free radicals (e.g., $\mathrm{O}-\mathrm{CH}_{3}, \mathrm{H}, \mathrm{OH}$, etc.) to be generated, which suggests that some radicals could react to the primary oil compositions with aromatic substitution and consequently increase the production of some species in oil. Higher temperature $\left(600^{\circ} \mathrm{C}\right)$ could more significantly enhance the reactions between free radicals and oil compositions, leading 
to a decrease of certain species, and meanwhile an increase of other species. As a result, a high content of 1,3-diphenylpropane (C15) $(10.8 \%)$ can be found only at $600{ }^{\circ} \mathrm{C}$ under pyrolysis of $\mathrm{KOH}$-immersed sludge (shown in Table 2). However, the influence of $\mathrm{KOH}$ on the pyrolysis chemical reactions is very complicated, and the effects from the distinct raw material, temperature, and heating method still need to be further studied.

\subsection{Potential Use for Pyrolysis Char}

The higher heating values of raw sludge, pyrolysis char, and oil were determined by a bomb calorimeter (IKA C-200). The heat value of dried sludge was about $15.68 \mathrm{MJ} \mathrm{kg}^{-1}$. The heat values of liquid oils were $40.86-41.39 \mathrm{MJ} \mathrm{kg}^{-1}$ after raw sludge pyrolysis at $400-600{ }^{\circ} \mathrm{C}$ (shown as Table 3), which was close to the values obtained with water emulsion diesel fuel $[36,37]$. For $\mathrm{KOH}$-immersed sludge, the liquid oil has a lower heat value (30.01-39.38 $\mathrm{MJ} \mathrm{kg}^{-1}$ ), and more $\mathrm{KOH}$ addition results in a significant decrease in the heat value. The char's heat values was also determined to assess the energy recovery. As seen in Table 3, more $\mathrm{KOH}$ addition and a high pyrolysis temperature resulted in a significant decrease in energy recoveries. Especially at $600{ }^{\circ} \mathrm{C}$, the energy recovery of char was low at $27 \%$ in the case of high $\mathrm{KOH}$ dose. As a result, this type of char may not be suitable for energy recycling, and it is better to develop other valuable material, such as adsorbent. In a previous study [38], a similar microwave heating system was also applied to sludge pyrolysis. The results indicated that a high temperature increases the energy consumption in microwave power and reduces the produced energy from pyrolysis residue (char) and oil. Therefore, lower energy consumption and higher energy recovery efficiency could be achieved at a lower pyrolysis temperature.

Table 3. Heat values and energy recoveries for liquid oil and char of raw sludge and $\mathrm{KOH}$-immersed sludge after various pyrolytic temperatures.

\begin{tabular}{|c|c|c|c|c|c|c|c|}
\hline \multirow{2}{*}{$\begin{array}{c}\text { KOH/Sludge } \\
\text { Ratio }\end{array}$} & \multirow{2}{*}{$\begin{array}{c}\text { Temperature } \\
\left({ }^{\circ} \mathrm{C}\right)\end{array}$} & \multicolumn{2}{|c|}{ Heat Value (MJ kg ${ }^{-1}$ ) } & \multicolumn{2}{|c|}{$\begin{array}{l}\text { Energy Content } \\
\left(\mathrm{MJ} \text { kg-drb }{ }^{-1} \text { ) }\right.\end{array}$} & \multicolumn{2}{|c|}{ Energy Recovery (\%) } \\
\hline & & Oil & Char & Oil & Char & Oil+Char & Char \\
\hline & 400 & $41.39 \pm 2.48$ & $12.15 \pm 1.34$ & $6.62 \pm 0.86$ & $8.38 \pm 0.75$ & $95 \pm 7.6$ & $53 \pm 7.4$ \\
\hline \multirow[t]{2}{*}{0} & 500 & $40.93 \pm 3.27$ & $11.58 \pm 1.39$ & $6.96 \pm 0.57$ & $7.29 \pm 1.02$ & $90 \pm 4.5$ & $46 \pm 5.1$ \\
\hline & 600 & $40.86 \pm 2.04$ & $11.07 \pm 0.77$ & $8.17 \pm 0.98$ & $6.64 \pm 0.53$ & $94 \pm 8.5$ & $42 \pm 3.8$ \\
\hline \multirow{3}{*}{0.25} & 400 & $39.38 \pm 4.33$ & $11.93 \pm 0.72$ & $5.51 \pm 0.72$ & $7.63 \pm 0.96$ & $84 \pm 10.1$ & $49 \pm 2.9$ \\
\hline & 500 & $36.05 \pm 1.85$ & $11.03 \pm 1.43$ & $5.76 \pm 0.63$ & $6.62 \pm 0.73$ & $79 \pm 4.7$ & $42 \pm 5.2$ \\
\hline & 600 & $30.03 \pm 2.14$ & $10.63 \pm 0.53$ & $5.12 \pm 0.36$ & $5.74 \pm 0.52$ & $69 \pm 7.6$ & $37 \pm 3.3$ \\
\hline \multirow{3}{*}{0.5} & 400 & $37.32 \pm 4.48$ & $10.83 \pm 1.32$ & $2.98 \pm 0.33$ & $6.71 \pm 1.02$ & $62 \pm 5.6$ & $43 \pm 5.6$ \\
\hline & 500 & $34.05 \pm 3.06$ & $9.93 \pm 0.89$ & $4.43 \pm 0.42$ & $5.46 \pm 0.65$ & $66 \pm 7.3$ & $35 \pm 4.9$ \\
\hline & 600 & $30.01 \pm 3.88$ & $9.43 \pm 0.67$ & $4.02 \pm 0.48$ & $4.24 \pm 0.63$ & $53 \pm 6.4$ & $27 \pm 2.4$ \\
\hline
\end{tabular}

The heat value multiplied by yield to obtain energy content on a dried raw sludge base ( $\left.\mathrm{drb}^{*}\right)$; the energy content was divided by $15.68 \mathrm{MJ} \mathrm{kg}^{-1}$ (heat value of dried raw sludge) to obtain the recovery \%.

\subsection{Characteristics of Sludge-Derived Adsorbents}

Ca was the predominant trace element with several percent in dried raw sludge. All of the trace elements have a slightly higher content in char (data not shown) as compared to

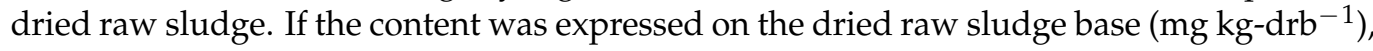
it was found that a small amount of trace elements would be lost during the pyrolysis process. The washing process is an important step in the preparation of adsorbents through chemical activation [39]. When the activation temperature is lower than the boiling point of the activator, the char should be washed to release the compounds remaining in the carbon network to improve the porous structure. In addition, some inorganic residues and elemental metals need to be removed. After high acid washing, the contents of seven hazardous elements in sludge adsorbent and high $\mathrm{KOH}$ dose sludge adsorbent $(\mathrm{KOH} /$ sludge ratio: 0.5$)$ were much lower as compared to dried raw sludge (as shown in 
Table 4). The contents of $\mathrm{Ni}$ and $\mathrm{Zn}$ were relatively high, and the content of $\mathrm{Zn}$ was much higher than other hazardous elements. However, the content of hazardous elements was slightly changed with increasing pyrolysis temperature.

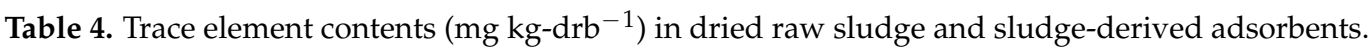

\begin{tabular}{|c|c|c|c|c|c|c|c|c|}
\hline \multirow{2}{*}{$\begin{array}{c}\text { KOH/Sludge } \\
\text { Ratio }\end{array}$} & $\begin{array}{c}\text { Temperature } \\
\left({ }^{\circ} \mathrm{C}\right)\end{array}$ & $\mathrm{Ni}$ & $\mathrm{Cu}$ & $\mathrm{Zn}$ & As & $\mathrm{Cd}$ & $\mathrm{Cr}$ & $\mathrm{Pb}$ \\
\hline & $\begin{array}{l}\text { Dried Raw } \\
\text { Sludge }\end{array}$ & $616.7 \pm 45.9$ & $124.3 \pm 6.1$ & $2859.4 \pm 217.9$ & $16.6 \pm 2.2$ & $15.5 \pm 1.9$ & $168.2 \pm 21.2$ & $174.8 \pm 7.2$ \\
\hline \multicolumn{9}{|c|}{0 (acid washing) } \\
\hline & $400^{\circ} \mathrm{C}$ & $357.9 \pm 27.4$ & $86.3 \pm 10.2$ & $1148.9 \pm 60.3$ & $12.4 \pm 0.8$ & $8.2 \pm 0.4$ & $122.2 \pm 7.2$ & $135.7 \pm 7.4$ \\
\hline & $500^{\circ} \mathrm{C}$ & $393.7 \pm 23.5$ & $93.2 \pm 3.9$ & $1202.6 \pm 78.5$ & $13.3 \pm 0.9$ & $8.8 \pm 0.8$ & $131.5 \pm 9.5$ & $139.2 \pm 10.2$ \\
\hline & $600^{\circ} \mathrm{C}$ & $388.5 \pm 27.6$ & $99.8 \pm 12.2$ & $1280.3 \pm 116.4$ & $14.5 \pm 1.2$ & $9.1 \pm 0.7$ & $138.6 \pm 17.7$ & $144.6 \pm 16.3$ \\
\hline \multicolumn{9}{|c|}{0.5 (acid washing) } \\
\hline & $400^{\circ} \mathrm{C}$ & $263.4 \pm 33.5$ & $93.4 \pm 5.7$ & $923.2 \pm 104.7$ & $13.7 \pm 0.7$ & $9.3 \pm 1.1$ & $115.1 \pm 13.1$ & $123.5 \pm 15.7$ \\
\hline & $500^{\circ} \mathrm{C}$ & $302.5 \pm 24.8$ & $102.7 \pm 6.4$ & $939.6 \pm 101.8$ & $14.5 \pm 1.1$ & $9.7 \pm 1.3$ & $119.4 \pm 8.6$ & $128.7 \pm 7.4$ \\
\hline & $600^{\circ} \mathrm{C}$ & $311.7 \pm 14.3$ & $110.5 \pm 8.1$ & $1006.5 \pm 84.3$ & $15.5 \pm 1.3$ & $10.3 \pm 0.8$ & $123.7 \pm 15.3$ & $133.4 \pm 5.8$ \\
\hline
\end{tabular}

As shown in a previous study [40], the heavy metals in sludge and char samples were sequentially extracted, and the fractions of heavy metals can be divided into four groups. F1 and F2 are soluble in water and weak acid and easily leach out. F3 is merely released under high acid and oxidized conditions. F4 is a fixed fraction and is difficult to leach out. The authors also indicated that some amounts of $\mathrm{F} 4 \mathrm{of} \mathrm{Ni}, \mathrm{Zn}, \mathrm{Cr}$, and $\mathrm{Mn}$ were further converted into F3 due to the addition of $\mathrm{KOH}$. Meanwhile, $\mathrm{Cd}$ was transformed a large part of F3 to F4 [40]. In this work, high acid was used in the washing of adsorbents, thus the elements of F1, F2, and F3 could be released. The contents of the seven elements in the sludge adsorbents decreased by about $22-60 \%$ as compared to dried raw sludge (as shown in Table 4). This loss could include exchangeable and carbonate-associated fractions (F1), oxides fraction (F2), and organics-associated fraction (F3), which was leached out by using strong acid. As compared to sludge adsorbents, the contents of $\mathrm{Ni}, \mathrm{Zn}, \mathrm{Cr}$, and $\mathrm{Pb}$ in high $\mathrm{KOH}$ dose sludge adsorbents still decreased by about 8-26\%, which showed that F3 could increase and can be released under high acid conditions. In contrary, the contents of $\mathrm{Cu}$, As, and $\mathrm{Cd}$ in high $\mathrm{KOH}$ dose adsorbents increased by about $7-13 \%$ as compared to sludge adsorbents. This could be due to an increase in the fixed fraction (F4) of $\mathrm{Cu}, \mathrm{As}$, and $\mathrm{Cd}$.

Table 5 shows the pore characteristics of the specific surface area, total pore volume (TPV), and micropore volume (MV) of the adsorbents. The results indicate that the sludge adsorbents have few micropores, with a low contribution to the total pore volume. When the pyrolytic temperature was higher than $400{ }^{\circ} \mathrm{C}$, the total pore volume increased at temperatures up to $600^{\circ} \mathrm{C}$, although the micropore (pore diameter (PD) $<20 \AA$ ) volume decreased (seen in Table 5). This suggests that the increase of the total pore volume resulted from the increase in mesopores (20-500 $\AA$ ). As a result, the specific surface area of the sludge adsorbents increased with an increase in the temperature, with the BET surface areas close to $25 \mathrm{~m}^{2} \mathrm{~g}^{-1}$ at $600{ }^{\circ} \mathrm{C}$. The activated effect was not significant with the addition of low dose $\mathrm{KOH}$. The low $\mathrm{KOH}$ dose sludge adsorbents have similar specific surface areas and total pore volume as compared with the sludge adsorbents. With the $\mathrm{KOH}$ dose increase, pore development resulted in an increase in the specific surface area. For the high $\mathrm{KOH}$ dose sludge adsorbents, the BET surface area increased 6.3-7.5 times, and the total pore volume increased 3.2-4.2 times compared with the sludge adsorbents at 400-600 ${ }^{\circ} \mathrm{C}$. As described in previous studies, the $\mathrm{KOH}$ activation of materials high in carbon (such as sludge) could result in the formation of $\mathrm{K}_{2} \mathrm{CO}_{3}$ and $\mathrm{K}_{2} \mathrm{O}$ and subsequently carbonaceous materials were etched by $\mathrm{KOH}, \mathrm{K}_{2} \mathrm{CO}_{3}$, and $\mathrm{K}_{2} \mathrm{O}$. At high temperatures, $\mathrm{K}_{2} \mathrm{CO}_{3}$ was reduced by carbons to form $\mathrm{K}_{2} \mathrm{O}, \mathrm{CO}$, and $\mathrm{CO}_{2}$, and $\mathrm{K}_{2} \mathrm{O}$ could be further reduced by carbons to form vapor of metallic $\mathrm{K}$ atoms $\left(>762^{\circ} \mathrm{C}\right)$. Meanwhile, the gaseous products caused by gasification were emitted so that more pores were formed. Additionally, 
$\mathrm{K}$ atoms intercalated into the internal structure of carbonaceous materials, leading to an increase in the surface areas [23,41].

Table 5. Pore characteristics of dried raw sludge and $\mathrm{KOH}$-immersed sludge after various pyrolytic temperatures.

\begin{tabular}{|c|c|c|c|c|c|}
\hline $\begin{array}{c}\mathrm{KOH} / \text { Sludge } \\
\text { Ratio }\end{array}$ & $\begin{array}{c}\text { Temperature } \\
{ }^{\circ} \mathrm{C}\end{array}$ & $\begin{array}{l}\text { BET Surface Area } \\
\left(\mathrm{m}^{2} \mathrm{~g}^{-1}\right)\end{array}$ & $\operatorname{TPV}\left(\mathrm{cm}^{3} \mathrm{~g}^{-1}\right) \times 10^{2}$ & $\operatorname{MV}\left(\mathrm{cm}^{3} \mathrm{~g}^{-1}\right) \times 10^{3}$ & PD (Å) \\
\hline \multirow{3}{*}{0} & 400 & $8.43 \pm 0.75$ & $5.36 \pm 0.21$ & $1.67 \pm 0.05$ & $254.14 \pm 14.63$ \\
\hline & 500 & $16.12 \pm 0.58$ & $9.75 \pm 0.83$ & $1.02 \pm 0.04$ & $241.82 \pm 17.09$ \\
\hline & 600 & $25.11 \pm 1.49$ & $10.89 \pm 0.61$ & $0.56 \pm 0.05$ & $173.52 \pm 9.27$ \\
\hline \multirow{3}{*}{0.25} & 400 & $11.22 \pm 0.56$ & $7.68 \pm 0.73$ & $0.10 \pm 0.01$ & $273.83 \pm 25.17$ \\
\hline & 500 & $12.89 \pm 0.94$ & $8.19 \pm 0.37$ & $0.14 \pm 0.01$ & $254.46 \pm 22.89$ \\
\hline & 600 & $22.29 \pm 1.52$ & $12.21 \pm 0.53$ & $0.20 \pm 0.01$ & $219.16 \pm 10.95$ \\
\hline \multirow{3}{*}{0.5} & 400 & $63.42 \pm 2.78$ & $22.62 \pm 0.97$ & $1.18 \pm 0.08$ & $142.65 \pm 5.35$ \\
\hline & 500 & $101.26 \pm 4.42$ & $31.09 \pm 2.10$ & $1.52 \pm 0.07$ & $122.83 \pm 6.63$ \\
\hline & 600 & $174.71 \pm 10.29$ & $39.27 \pm 2.21$ & $2.05 \pm 0.09$ & $89.91 \pm 7.19$ \\
\hline
\end{tabular}

Due to the pore creation and new pore formation under the activation process, the average pore diameter decreased with an increase in the $\mathrm{KOH}$ dose. Compared with sludge adsorbents, the high $\mathrm{KOH}$ dose sludge adsorbent had a higher total pore volume and higher micropore volume at $400-600{ }^{\circ} \mathrm{C}$ (shown as Table 5 and Figure 1). However, the increment of the total pore volume was several hundred times larger than the increment of the micropore volume. This also suggests that the high $\mathrm{KOH}$ dose sludge adsorbent significantly increases the volume of mesopores but slightly increases the volume of micropores. As a result, for the high $\mathrm{KOH}$ dose sludge adsorbents, the BET surface area and total pore volume were $174.7 \mathrm{~m}^{2} \mathrm{~g}^{-1}$ and $0.39 \mathrm{~cm}^{3} \mathrm{~g}^{-1}$ at $600{ }^{\circ} \mathrm{C}$, respectively (seen in Table 5). The temperature range of this study is $400-600{ }^{\circ} \mathrm{C}\left(<762{ }^{\circ} \mathrm{C}\right)$, thus decreasing the reduction of $\mathrm{K}_{2} \mathrm{CO}_{3}$ and $\mathrm{K}_{2} \mathrm{O}$ in carbonaceous materials and the penetration of potassium metal into the internal structure of the carbon lattice. It is reasonable to infer that at a temperature higher than $762{ }^{\circ} \mathrm{C}$, the development of pores may tend to increase the micropore volume and expand the specific surface area.

(a)

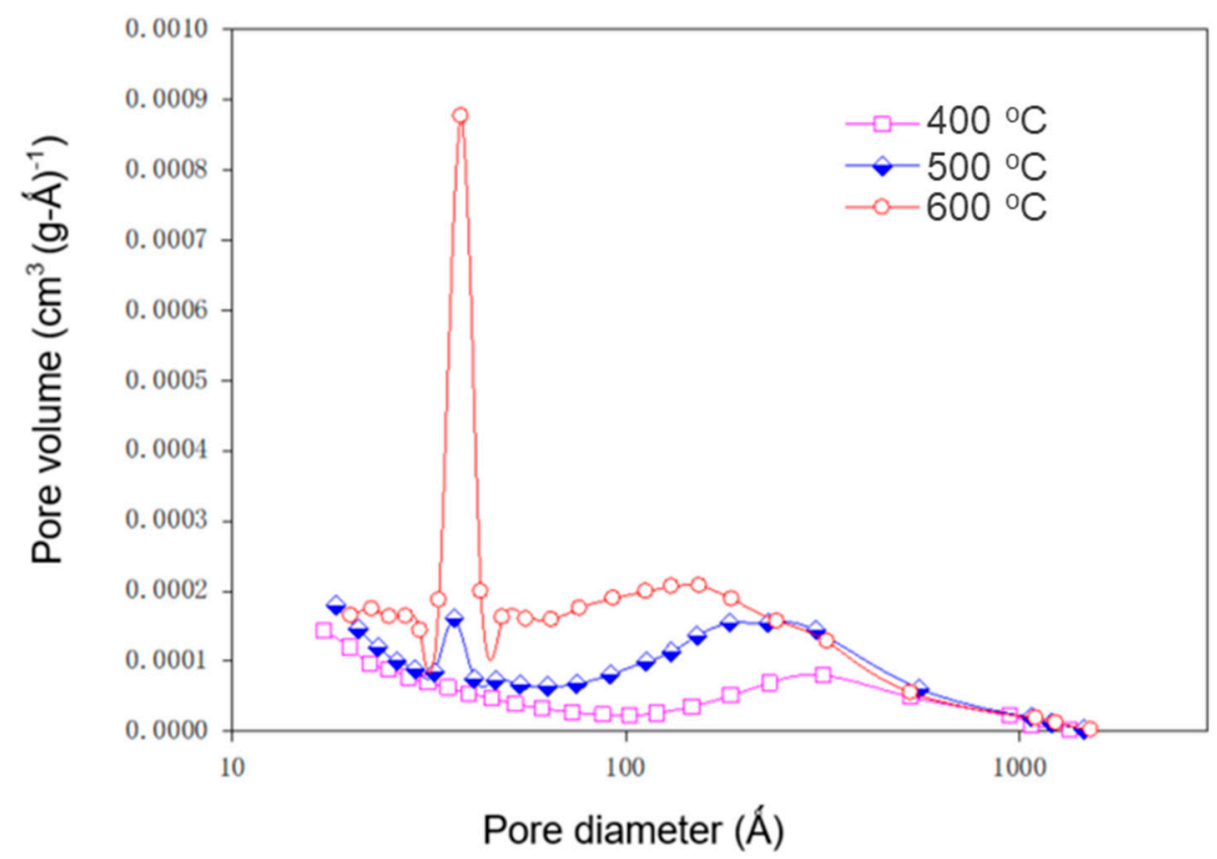

Figure 1. Cont. 
(b)

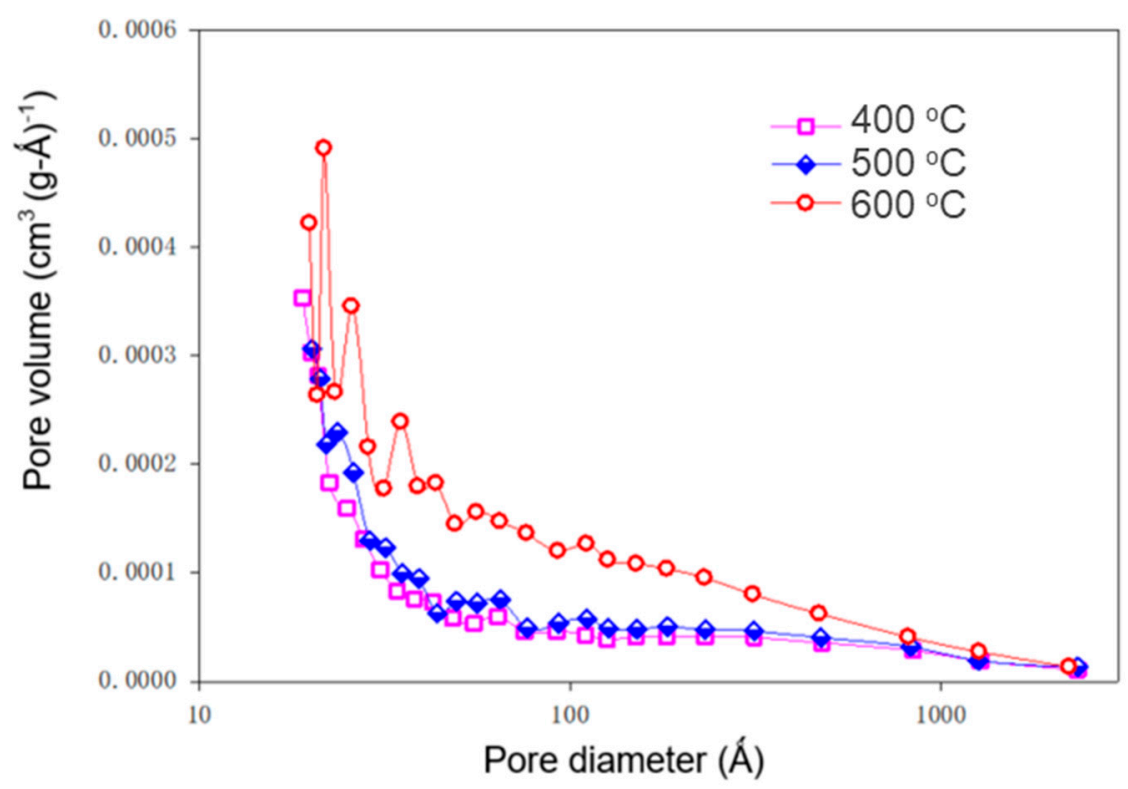

(c)

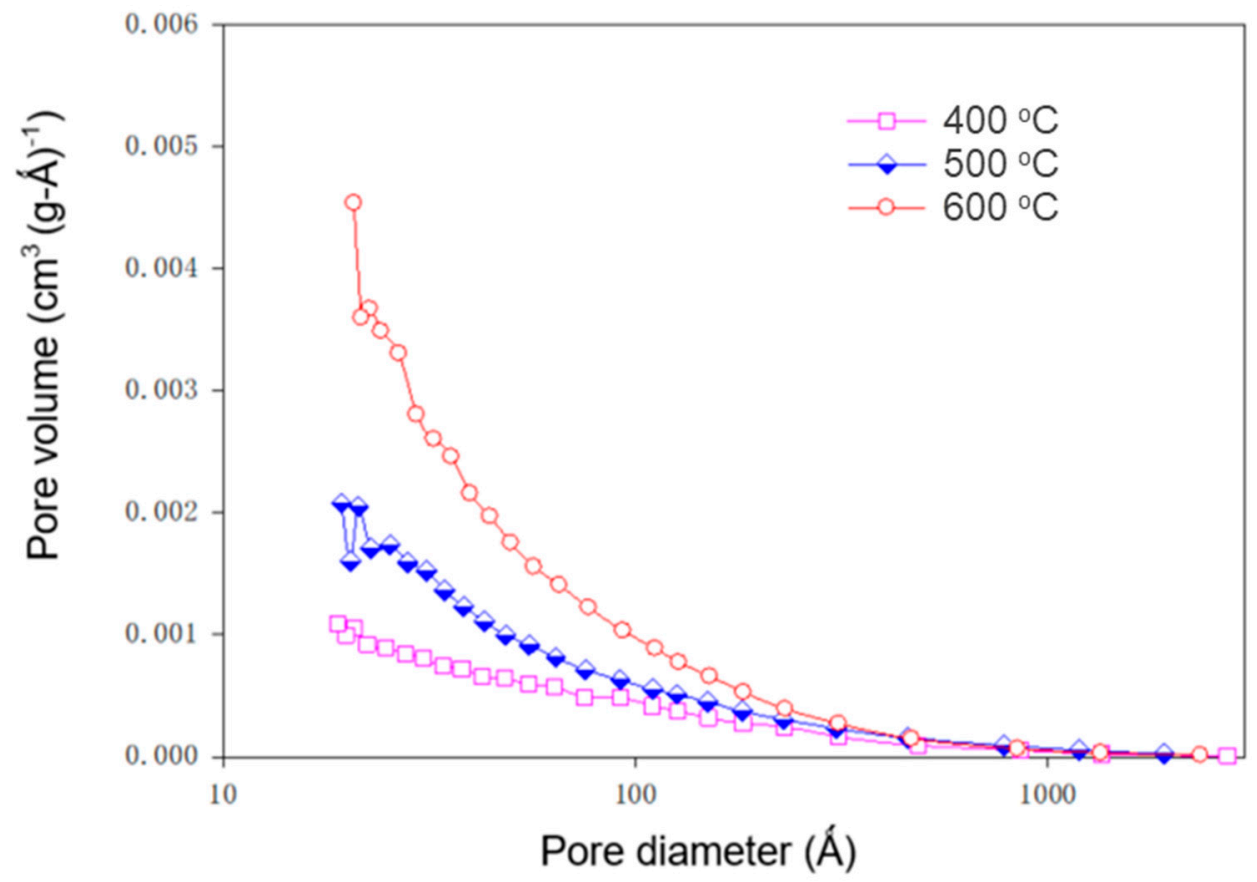

Figure 1. Pore size distribution of sludge adsorbent and $\mathrm{KOH}$-immersed sludge adsorbent. (a) Sludge adsorbent; (b) Low $\mathrm{KOH}$ dose sludge adsorbent; (c) High $\mathrm{KOH}$ dose sludge adsorbent.

\subsection{Metal Adsorption Capacity}

The adsorbents derived at $600{ }^{\circ} \mathrm{C}$ have high surface area and pore volume, which is suitable for evaluating the removal effect of heavy metals in water. The $\mathrm{Cd}(\mathrm{II}), \mathrm{Pb}(\mathrm{II}), \mathrm{Ni}(\mathrm{II})$, and $\mathrm{Zn}(\mathrm{II})$ adsorption isotherms were investigated at different initial metal concentrations ranging from 50 to $800 \mathrm{mg} \mathrm{L}^{-1}$ (shown in Figure 2). The fitting parameters and coefficients of determination $\left(r^{2}\right)$ for $\mathrm{Cd}(\mathrm{II}), \mathrm{Pb}(\mathrm{II}), \mathrm{Ni}(\mathrm{II})$, and $\mathrm{Zn}(\mathrm{II})$ onto distinct adsorbents obtained from the Langmuir model are shown in Table 6. The coefficients of determination indicate that the Langmuir model is suitable for description of the adsorption isotherms, with $r^{2}$ from 0.956 to 0.997 . The experimental values are in good agreement with the calculated 
values as shown in Figure 2. The adsorption isotherms of metal ions on the high $\mathrm{KOH}$ dose sludge adsorbent showed a sharp increase in adsorption capacity, leading to most of the metal ions' removal at low equilibrium concentrations (Figure 2c). When the equilibrium concentrations of metal ions exceed $100 \mathrm{mg} \mathrm{L}^{-1}$, almost no additional metal ions are removed. This phenomenon suggested that precipitation was the dominant adsorption mechanism due to the release of alkaline anion, such asa carbonate, that could precipitate metal ions with strong chemical affinity [42].

(a)

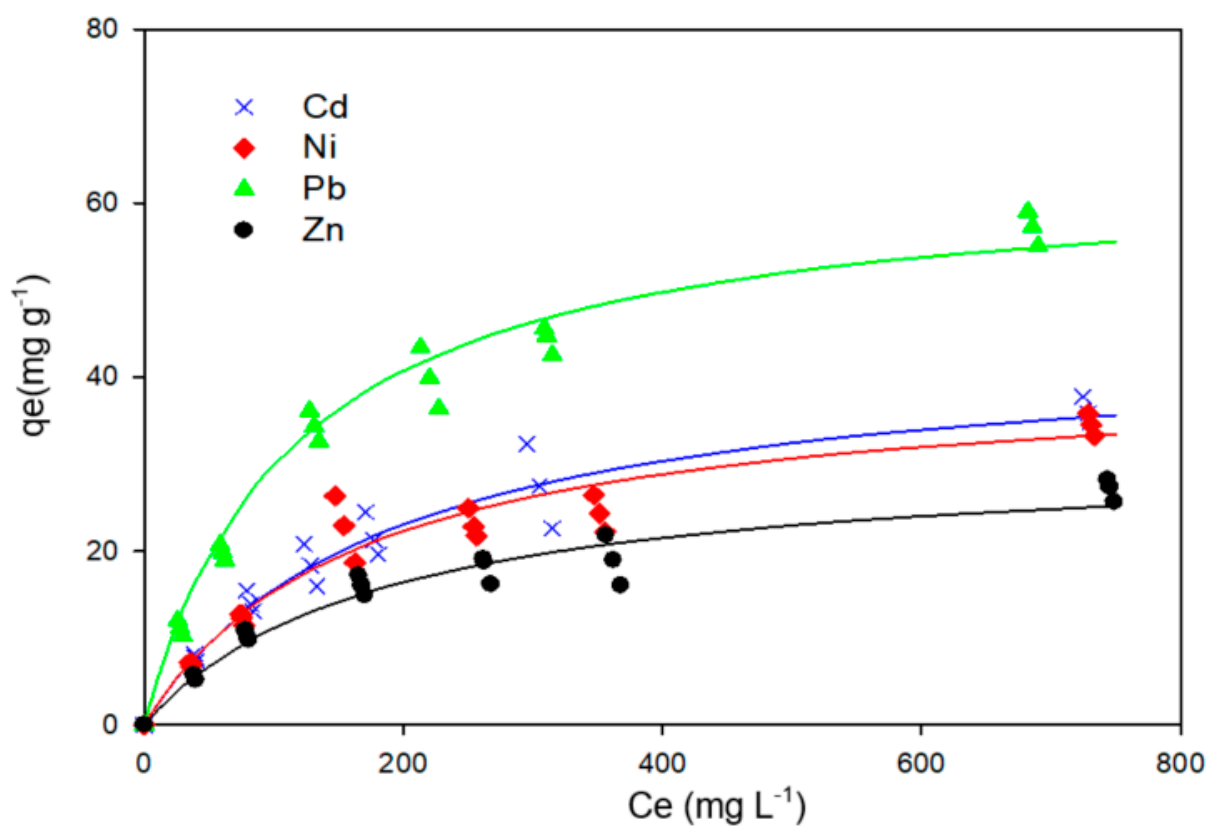

(b)

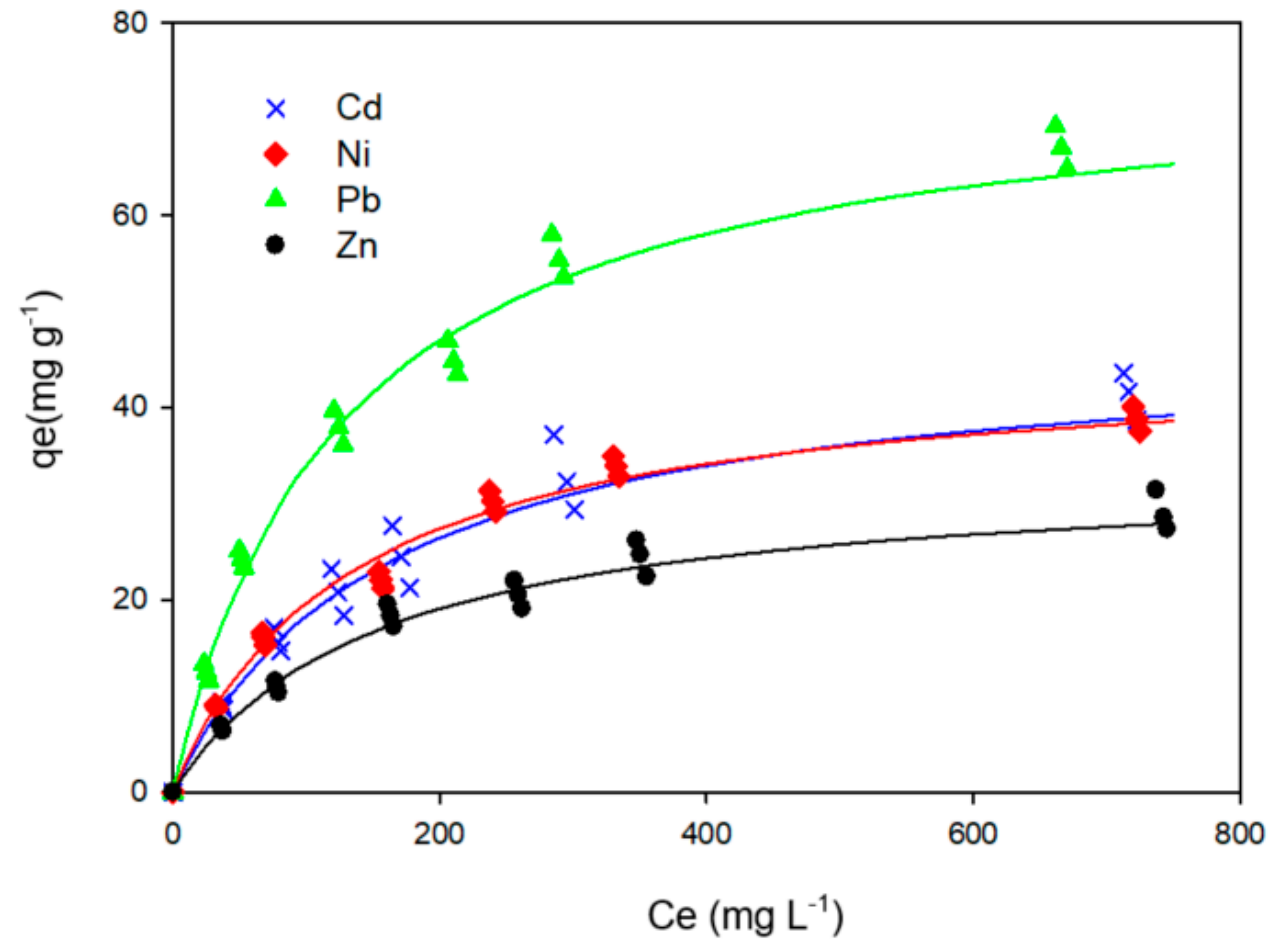

Figure 2. Cont. 
(c)

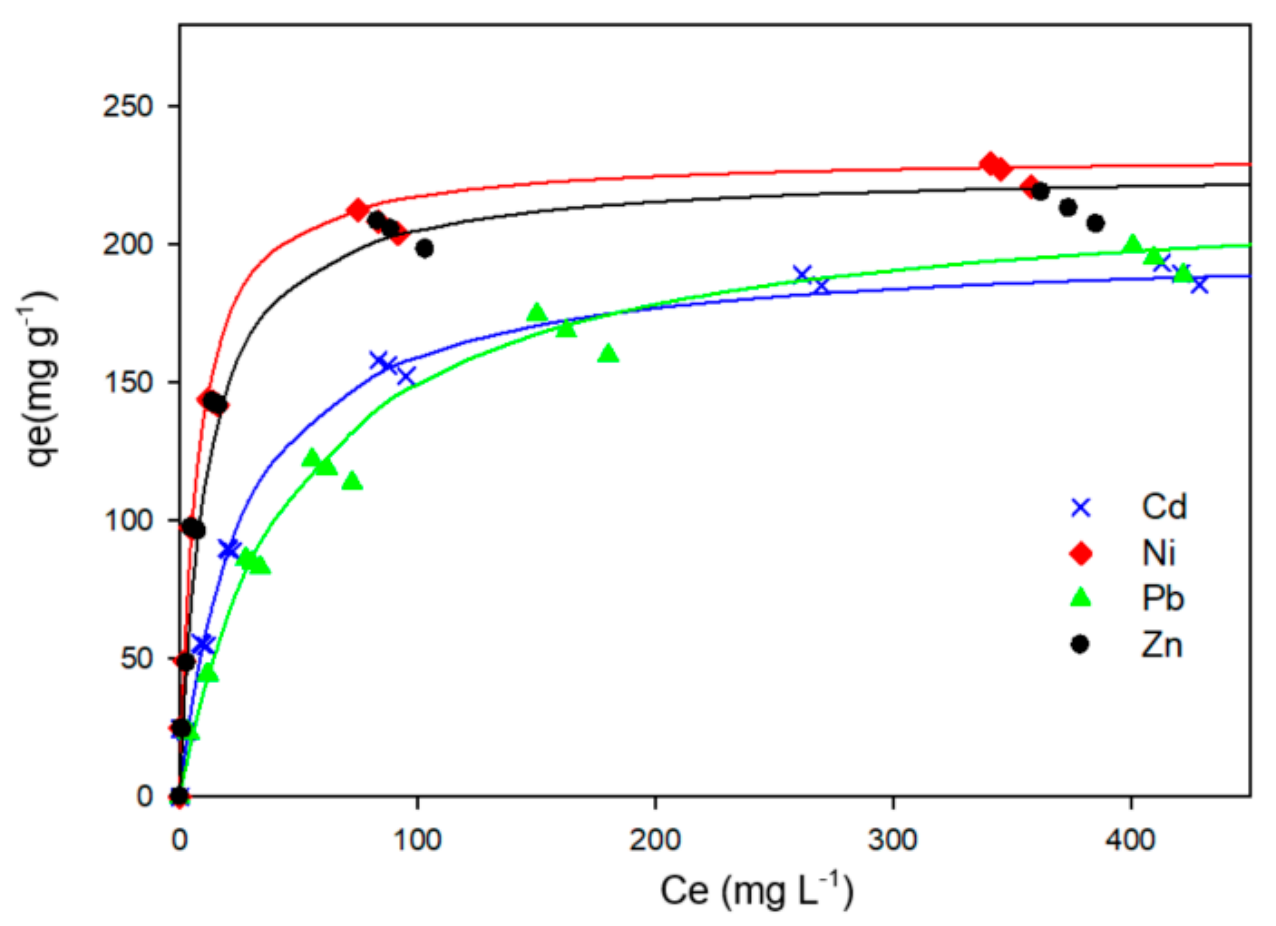

Figure 2. Metal adsorption isotherms of sludge adsorbent and $\mathrm{KOH}$-immersed sludge adsorbent. The experimental and calculated values were plotted as points and lines, respectively. The Langmuir parameters were estimated with the linear regression method by using Equation (2) and the qe was calculated from Equation (1). (a) Sludge adsorbent; (b) Low KOH dose sludge adsorbent; (c) High $\mathrm{KOH}$ dose sludge adsorbent.

Table 6. Parameters of metal ions adsorption isotherms fitted with the Langmuir model for the adsorbents at pyrolytic temperatures of $600^{\circ} \mathrm{C}$.

\begin{tabular}{ccccc}
\hline $\begin{array}{c}\text { KOH/Sludge } \\
\text { Ratio }\end{array}$ & Metal Solution & $\boldsymbol{K}\left(\mathbf{L ~ m m o l}^{-\mathbf{1}}\right)$ & $\boldsymbol{q}_{\boldsymbol{m}}$ ( $\left.\mathbf{m m o l} \mathbf{g}^{-\mathbf{1}}\right)$ & $\boldsymbol{r}^{\mathbf{2}}$ \\
\hline & $\mathrm{Cd}(\mathrm{II})$ & 0.607 & 0.395 & 0.969 \\
0 & $\mathrm{~Pb}(\mathrm{II})$ & 1.580 & 0.309 & 0.964 \\
& $\mathrm{Ni}(\mathrm{II})$ & 0.353 & 0.673 & 0.975 \\
$\mathrm{Zn}(\mathrm{II})$ & 0.362 & 0.478 & 0.973 \\
\hline & $\mathrm{Cd}(\mathrm{II})$ & 0.704 & 0.423 & 0.967 \\
0.25 & $\mathrm{~Pb}(\mathrm{II})$ & 1.668 & 0.367 & 0.956 \\
& $\mathrm{Ni}(\mathrm{II})$ & 0.449 & 0.772 & 0.988 \\
& $\mathrm{Zn}(\mathrm{II})$ & 0.430 & 0.514 & 0.983 \\
\hline & $\mathrm{Cd}(\mathrm{II})$ & 4.439 & 1.774 & 0.982 \\
& $\mathrm{~Pb}(\mathrm{II})$ & 4.307 & 1.068 & 0.985 \\
& $\mathrm{Ni}(\mathrm{II})$ & 8.473 & 3.962 & 0.995 \\
& $\mathrm{Zn}(\mathrm{II})$ & 6.128 & 3.472 & 0.997 \\
\hline
\end{tabular}

As mentioned earlier, the raw sludge in this study contains several percentages of calcium. After acid washing, the three test adsorbents contained about $1.6-2.9 \%$ of calcium, thus calcium carbonate may be a source of carbonate in the adsorbents. The potassium was about $0.3-1.2 \%$ for the two $\mathrm{KOH}$ activation adsorbents. A low $\mathrm{KOH}$ dose causes a lower activation effect and less $\mathrm{K}_{2} \mathrm{CO}_{3}$ and $\mathrm{K}_{2} \mathrm{O}$ in char, and poor development of porosity. When compared to raw sludge adsorbent, the adsorption capacities of $\mathrm{KOH}$-immersed sludge adsorbents increased for each ion, but no significant change was found for the case of the low $\mathrm{KOH}$ dose. In other words, besides precipitation, there should be another important 
adsorption mechanism for the raw sludge adsorbent and low $\mathrm{KOH}$ dose sludge adsorbent. The adsorption isotherm of metal ions on the sludge adsorbent showed that the adsorption capacity increased slowly with the increase of the equilibrium concentration, and a small amount of metal ions were continuously removed at a higher equilibrium concentration (Figure 2a). This phenomenon could be explained by the presence of adsorption with weaker affinity, such as the exchange between $\mathrm{H}^{+}$and metal ions through deprotonating on aromatic [43] and carboxylic groups. The initial $\mathrm{pH}$ of the solution added with the sludge adsorbent was about 6.0. As part of the metal ions used at low concentration were consumed by the alkaline anions, the $\mathrm{H}^{+}$exchange capacity was reduced, so the equilibrium $\mathrm{pH}$ slightly dropped to 5.8. At the high concentration, the relatively high $\mathrm{H}^{+}$release caused the equilibrium $\mathrm{pH}$ to drop to 5.5. Although a similar $\mathrm{pH}$ drop can also be found when using a low $\mathrm{KOH}$ dose sludge adsorbent, this drop is not sufficient to explain the difference in the adsorption capacity between the sludge and the low $\mathrm{KOH}$ dose sludge adsorbent (Figure 2a,b). Therefore, for the low $\mathrm{KOH}$ dose sludge, the exchange of metal ions with $\mathrm{Ca}^{+2}$ and $\mathrm{K}^{+1}$ on the carbon material surface may be more important. In addition, when using high $\mathrm{KOH}$ dose sludge adsorbent, it was found that low-concentration solutions caused an increase in equilibrium $\mathrm{pH}$ (about 6.8), while high-concentration solutions slightly decreased (about 5.6). This is consistent with previous observations that at low concentration, almost all metal ions are precipitated, and excess alkaline anions cause the $\mathrm{pH}$ to rise. At a high concentration, metal ions can consume all available alkaline anions in the solution, so additional ion exchange occurs $\left(\mathrm{H}^{+}\right.$release), which leads to a slight drop in $\mathrm{pH}$. The results also indicated that a high $\mathrm{KOH}$ dose significantly enhanced pore development during the pyrolysis process and consequently increased the metal adsorption. The high $\mathrm{KOH}$ dose sludge adsorbent was mesoporous carbon material, which avoided the adsorption sites from being shielded or the pore channel blocked to a certain extent, and promoted the adsorption capacity.

The parameter $K$ is related to the affinity of the adsorption sites to the metal ion. Among the studied adsorbents, the high $\mathrm{KOH}$ dose significantly improved the affinity of the adsorbent, and the highest $K$ values can be found for the high $\mathrm{KOH}$ dose sludge adsorbent to each metal ion (seen in Table 6). For the low $\mathrm{KOH}$ dose sludge adsorbent, the $q_{m}$ increased slightly as compared with the sludge adsorbent. For high $\mathrm{KOH}$ dose sludge adsorbent, the $q_{m}$ increased to 3.5-7.3 times the sludge adsorbent for different metal ions (221.33 $\mathrm{mgg}^{-1}$ for $\mathrm{Pb}(\mathrm{II}), 199.45 \mathrm{mgg}^{-1} \mathrm{Cd}(\mathrm{II}), 227.04 \mathrm{mgg}^{-1} \mathrm{Zn}(\mathrm{II})$, and $232.53 \mathrm{mgg}^{-1}$ $\mathrm{Ni}(\mathrm{II})$ ). The unit of maximum adsorption capacities $\left(q_{m}\right)$ was converted to mmolg ${ }^{-1}$, which allowed a comparison of the adsorptive sites of the distinct adsorbents to a single ion. The $q_{m}$ of sludge adsorbents was $0.309 \mathrm{mmolg}^{-1} \mathrm{for} \mathrm{Pb}(\mathrm{II}), 0.395 \mathrm{mmolg}^{-1} \mathrm{Cd}$ (II), $0.478 \mathrm{mmolg}^{-1} \mathrm{Zn}$ (II), and $0.673 \mathrm{mmolg}^{-1} \mathrm{Ni}(\mathrm{II})$ (shown in Table 6). The high $\mathrm{KOH}$ dose sludge adsorbent has the highest $\mathrm{q}_{\mathrm{m}}$ values for an individual metal ion, which differs with the following order: $\mathrm{Ni}$ (II) $\left(3.962 \mathrm{mmolg}^{-1}\right)>\mathrm{Zn}$ (II) $\left(3.472 \mathrm{mmolg}^{-1}\right)>\mathrm{Cd}$ (II) $\left(1.774 \mathrm{mmolg}^{-1}\right)>\mathrm{Pb}$ (II) $\left(1.068 \mathrm{mmolg}^{-1}\right)$. A previous study reported that the adsorption increased as the ionic radius decreased [44]. In this work, the ionic radius of the metals varied in the following order: $\mathrm{Ni}(\mathrm{II})<\mathrm{Zn}$ (II) $<\mathrm{Cd}(\mathrm{II})<\mathrm{Pb}$ (II), and the $q_{m}$ was in the order: $\mathrm{Ni}(\mathrm{II})>\mathrm{Zn}(\mathrm{II})>\mathrm{Cd}(\mathrm{II})>\mathrm{Pb}(\mathrm{II})$. This result agrees with the previous research report. However, the detailed reasons for this phenomenon are not clear and need to be further studied. Direct comparisons with other published results are not appropriate due to changes in parameters and experimental conditions. The adsorption capacities of the biochar produced from Sidahermaphrodita were respectively 48.08 and $35.71 \mathrm{mgg}^{-1}$ for $\mathrm{Zn}$ (II) and $\mathrm{Cd}(\mathrm{II})$ [45]. The adsorption capacity was $53.6 \mathrm{mgg}^{-1}$ of $\mathrm{Pb}(\mathrm{II})$ on hickory wood biochar using alkali modification [46]. However, compared to the above-mentioned biochar, the high $\mathrm{KOH}$ dose sludge adsorbent (pyrolyzed at $600^{\circ} \mathrm{C}$ ) has a higher adsorption capacity. 


\section{Conclusions}

The microwave heating system used for sludge pyrolysis can integrate dehydration and carbonization steps, which simplify the operating procedures and are cost-effective. With pyrolysis by $\mathrm{KOH}$ activation, under a high temperature and high $\mathrm{KOH}$ dose, most of the lost mass from sludge was transformed into gaseous products instead of liquid oil. The heat values of liquid oils were $40.86-41.39 \mathrm{MJ} \mathrm{kg}^{-1}$, which suggests their potential for use as fuels after distillation. The energy recovery of char was low at $27 \%$ in the case of sludge pyrolysis with a high $\mathrm{KOH}$ dose. This type of char may not be suitable for energy recycling, and it is more suited for development to be an adsorbent. The pyrolysis of sludge by $\mathrm{KOH}$ activation is beneficial to the porosity development and generates a mesopore structure. A high $\mathrm{KOH}$ dose could be necessary to enhance the development of the pore structure. The adsorption mechanism of the adsorbent tested in this study may mainly include precipitation and two types of ion exchange (referred to as replacement of $\mathrm{H}^{+}$, and replacement of $\mathrm{Ca}^{+2}$ and $\mathrm{K}^{+}$). However, for the studied adsorbents, the precipitation could be the dominant adsorption mechanism due to the binding between alkaline anions, such as carbonate, and metal ions with strong chemical affinity. The high $\mathrm{KOH}$ dose sludge adsorbent has remarkable adsorption performance and can be used as adsorbents for the removal of the studied metals.

Author Contributions: Conceptualization, K.-H.L. and H.-L.C.; methodology, H.-L.C.; software, K.-H.L.; validation, K.-H.L., H.-L.C. and J.-H.T.; formal analysis, K.-H.L. and H.-L.C.; investigation, Z.-W.C., K.-H.L., H.-L.C.; resources, K.-H.L., H.-L.C.; data curation, H.-L.C.; writing-original draft preparation, H.-L.C.; writing-review and editing, K.-H.L. and H.-L.C.; visualization, K.-H.L.; supervision, J.-H.T.; project administration, H.-L.C.; funding acquisition, H.-L.C. All authors have read and agreed to the published version of the manuscript.

Funding: The authors express their sincere thanks to the Ministry of Science and Technology, Executive Yuan, Republic of China (Taiwan), for research fund support (MOST-102-2221-E-039-002-MY3 and 105-2221-E-039-001-MY3).

Institutional Review Board Statement: Not applicable.

Informed Consent Statement: Not applicable.

Data Availability Statement: Not applicable.

Conflicts of Interest: The authors declare no conflict of interest.

\section{References}

1. Campos, J.L.; Otero, L.; Franco, A.; Mosquera-Corral, A.; Roca, E. Ozonation strategies to reduce sludge production of a seafood industry WWTP. Bioresour. Technol. 2009, 100, 1069-1073. [CrossRef]

2. Romero, P.; Coello, M.D.; Quiroga, J.M.; Aragon, C.A. Overview of sewage sludge minimisation: Techniques based on cell lysis-cryptic growth. Desal. Water Treat. 2013, 51, 5918-5933. [CrossRef]

3. Pokorna, E.; Postelmans, N.; Jenicek, P.; Schreurs, S.; Carleer, R.; Yperman, J. Study of bio-oils and solids from flash pyrolysis of sewage sludges. Fuel 2009, 88, 1344-1350. [CrossRef]

4. Tchobanoglous, G.; Burton, F.L.; Stensel, H.D. Wastewater Engineering: Treatment and Reuse, 4th ed.; Metcalf \& Eddy Inc.; McGraw-Hill Higher Education: New York, NY, USA, 2003; ISBN 978-0070418783.

5. Domínguez, A.; Menendez, J.A.; Inguanzo, M.; Pis, J.J. Production of bio-fuels by high temperature pyrolysis of sewage sludge using conventional and microwave heating. Bioresour. Technol. 2006, 97, 1185-1193. [CrossRef]

6. Park, E.S.; Kang, B.S.; Kim, J.S. Recovery of oils with high caloric value and low contaminant content by pyrolysis of digested and dried sewage sludge containing polymer flocculants. Energy Fuels 2008, 22, 1335-1340. [CrossRef]

7. Manara, P.; Zabaniotou, A. Towards sewage sludge based biofuels via thermochemical conversion: A review. Renew. Sustain. Energy Rev. 2012, 16, 2566-2582. [CrossRef]

8. Tyagi, V.K.; Lo, S.L. Microwave irradiation: A sustainable way for sludge treatment. Renew. Sustain. Energy Rev. 2013, 18, 288-305. [CrossRef]

9. Gao, N.; Kamran, K.; Quan, C.; Williams, P.T. Thermochemical conversion of sewage sludge: A critical review. Prog. Energy Combust. Sci. 2020, 79, 100843. [CrossRef]

10. Hwang, I.H.; Ouchi, Y.; Matsuto, T. Characteristics of leachate from pyrolysis residue of sewage sludge. Chemosphere 2007, 68, 1913-1919. [CrossRef] 
11. Fytili, D.; Zabaniotou, A. Utilization of sewage sludge in EU application of old and new methods: A review. Renew. Sustain. Energy Rev. 2008, 12, 116-140. [CrossRef]

12. Kim, Y.; Parker, W.A. Technical and economic evaluation of the pyrolysis of sewage sludge for the production of bio-oil. Bioresour. Technol. 2008, 99, 1409-1416. [CrossRef] [PubMed]

13. Kinoshita, K. Carbon: Electrochemical and Physicochemical Properties; John Wiley \& Sons: New York, NY, USA, 1987; ISBN 978-0-47184802-8.

14. Gao, Y.; Yue, Q.; Gao, B.; Li, A. Insight into activated carbon from different kinds of chemical activating agents: A review. Sci. Total Environ. 2020, 746, 141094. [CrossRef] [PubMed]

15. Wu, X.; Zhu, F.; Qi, J.; Zhao, L.; Yan, F.; Li, C. Challenge of biodiesel production from sewage sludge catalyzed by $\mathrm{KOH}$, $\mathrm{KOH} /$ activated carbon, and $\mathrm{KOH} / \mathrm{CaO}$. Front. Environ. Sci. Eng. 2017, 11, 3. [CrossRef]

16. Nuithitikul, K.; Prasitturattanachai, W. Activity of sulfated aluminium-tin mixed oxides for the esterification of free fatty acids in crude palm oil. Int. J. Green Energy 2014, 11, 1097-1106. [CrossRef]

17. Islam, A.; Taufiq-Yap, Y.H.; Chu, C.M.; Chan, E.S.; Ravindra, P. Studies on design of heterogeneous catalysts for biodiesel production. Process Saf. Environ. Prot. 2013, 91, 131-144. [CrossRef]

18. Juan, J.C.; Kartika, D.A.; Wu, T.Y.; Hin, T.Y. Biodiesel production from Jatropha oil by catalytic and non-catalytic approaches: An overview. Bioresour. Technol. 2011, 102, 452-460. [CrossRef]

19. Acosta, R.; Fierro, V.; de Yuso, A.M.; Nabarlatz, D. Tetracycline adsorption onto activated carbons produced by KOH activation of tyre pyrolysis char. Chemosphere 2016, 149, 168-176. [CrossRef] [PubMed]

20. Njoku, V.O.; Foo, K.Y.; Asif, M.; Hameed, B.H. Preparation of activated carbons from rambutan (Nepheliumlappaceum) peel by microwave-induced $\mathrm{KOH}$ activation for acid yellow 17 dye adsorption. Chem. Eng. J. 2014, 250, 198-204. [CrossRef]

21. Devi, P.; Saroha, A.K. Utilization of sludge based adsorbents for the removal of various pollutants: A review. Sci. Total Environ. 2017, 578, 16-33. [CrossRef]

22. Lillo-Ródenas, M.A.; Ros, A.; Fuente, E.; Montes-Morán, M.A.; Martin, M.J.; Linares-Solano, A. Further insights into the activation process of sewage sludge based precursors by alkaline hydroxides. Chem. Eng. J. 2008, 142, 168-174. [CrossRef]

23. Xu, G.; Yang, X.; Spinosa, L. Development of sludge-based adsorbents: Preparation, characterization, utilization and its feasibility assessment: A review. J. Environ. Manag. 2015, 151, 221-232. [CrossRef]

24. Brubauer, S.; Emmett, H.P.; Teller, E. Adsorption of gas in multimolecular layers. J. Am. Chem. Soc. 1938, 60, 309-319. [CrossRef]

25. Lin, Q.H.; Cheng, H.; Chen, G.Y. Preparation and characterization of carbonaceous adsorbents from sewage sludge using a pilot-scale microwave heating equipment. J. Anal. Appl. Pyrolysis 2012, 93, 113-119. [CrossRef]

26. Li, H.; Dong, X.; da Silva, E.B.; de Oliveira, L.M.; Chen, Y.; Ma, L.Q. Mechanisms of metal sorption by biochars: Biochar characteristics and modifications. Chemosphere 2017, 178, 466-478. [CrossRef] [PubMed]

27. Inyang, M.I.; Gao, B.; Yao, Y.; Xue, Y.; Zimmerman, A.; Mosa, A.; Pullammanappallil, P.; Ok, Y.S.; Cao, X. A review of biochar as a low-cost adsorbent for aqueous heavy metal removal. Crit. Rev. Environ. Sci. Technol. 2016, 46, 406-433. [CrossRef]

28. Chen, T.; Zhou, Z.; Xu, S.; Wang, H.; Lu, W. Adsorption behavior comparison of trivalent and hexavalent chromium on biochar derived from municipal sludge. Bioresour. Technol. 2015, 190, 388-394. [CrossRef]

29. Li, L.Y.; Gong, X.; Abida, O. Waste-to-resources: Exploratory surface modification of sludge-based activated carbon by nitric acid for heavy metal adsorption. Waste Manag. 2019, 87, 375-386. [CrossRef]

30. ASTM D3173-02. Standard Test Method for Moisture in the Analysis Sample of Coal and Coke; ASTM International: West Conshohocken, PA, USA, 2002.

31. ASTM D3174-02. Standard Test Method for Ash in the Analysis Sample of Coal and Coke from Coal; ASTM International: West Conshohocken, PA, USA, 2002.

32. ASTM D3175-02. Standard Test Method for Volatile Matter in the Analysis Sample of Coal and Coke; ASTM International: West Conshohocken, PA, USA, 2002.

33. Barrett, E.P.; Jovner, L.G.; Halenda, P.P. The determination of pore volume and area distribution in porous substances I. computations of nitrogen isotherms. J. Am. Chem. Soc. 1951, 73, 373-380. [CrossRef]

34. Lin, B.; Wang, J.; Huang, Q.; Chi, Y. Effects of potassium hydroxide on the catalytic pyrolysis of oily sludge for high-quality oil product. Fuel 2017, 200, 124-133. [CrossRef]

35. Chen, W.; Gong, M.; Li, K.; Xia, M.; Chen, Z.; Xiao, H.; Fang, Y.; Chen, Y.; Yang, H.; Chen, H. Insight into KOH activation mechanism during biomass pyrolysis: Chemical reactions between O-containing groups and KOH. Appl. Energy 2020, $278,115730$. [CrossRef]

36. Stabile Fuel Emulsions and Method of Making. U.S. Patent 6,607,566, 2003.

37. Fuel Comprising Emulsion between Water and a Liquid Hydrocarbon. U.S. Patent 7,018,433, 2006.

38. Lin, K.H.; Lai, N.; Zeng, J.Y.; Chiang, H.L. Microwave-pyrolysis treatment of biosludge from a chemical industrial wastewater treatment plant for exploring product characteristics and potential energy recovery. Energy 2020, 199, 117446. [CrossRef]

39. Kwon, S.H.; Lee, E.; Kim, B.; Kim, S.; Lee, B.; Kim, M.; Jung, J.C. Preparation of activated carbon aerogel and its application to electrode material for electric double layer capacitor in organic electrolyte: Effect of activation temperature. Korean J. Chem. Eng. 2015, 32, 248-254. [CrossRef] 
40. Li, Z.; Deng, H.; Yang, L.; Zhang, G.; Li, Y.; Ren, Y. Influence of potassium hydroxide activation on characteristics and environmental risk of heavy metals in chars derived from municipal sewage sludge. Bioresour. Technol. 2018, 256, $216-223$. [CrossRef] [PubMed]

41. Deng, H.; Li, G.; Yang, H.; Tang, J.; Tang, J. Preparation of activated carbons from cotton stalk by microwave assisted KOH and $\mathrm{K}_{2} \mathrm{CO}_{3}$ activation. Chem. Eng. J. 2010, 163, 373-381. [CrossRef]

42. Inyang, M.; Gao, B.; Yao, Y.; Xue, Y.; Zimmerman, A.R.; Pullammanappallil, P.; Cao, X. Removal of heavy metals from aqueous solution by biochars derived from anaerobically digested biomass. Bioresour. Technol. 2012, 110, 50-56. [CrossRef] [PubMed]

43. Vuković, G.D.; Marinković, A.D.; Škapin, S.D.; Ristić, M.T.; Aleksić, R.; Perić-Grujić, A.A. Removal of lead from water by amino modified multi-walled carbon nanotubes. Chem. Eng. J. 2011, 173, 855-865. [CrossRef]

44. Guzel, F.; Yakut, H.; Topal, G. Determination of kinetic and equilibrium parameters of the batch adsorption of Mn(II), Co(II), Ni(II) and $\mathrm{Cu}$ (II) from aqueous solution by black carrot (Daucuscarota L.) residues. J. Hazard. Mater. 2008, 153, 1275-1287. [CrossRef]

45. Bogusz, A.; Oleszczuk, P.; Dobrowolski, R. Application of laboratory prepared and commercially available biochars to adsorption of cadmium, copper and zinc ions from water. Bioresour. Technol. 2015, 196, 540-549. [CrossRef]

46. Ding, Z.H.; Hu, X.; Wan, Y.S.; Wang, S.S.; Gao, B. Removal of lead, copper, cadmium, zinc, and nickel from aqueous solutions by alkali-modified biochar: Batch and column tests. J. Ind. Eng. Chem. 2016, 33, 239-245. [CrossRef] 